\title{
Better tolerance of preservative-free latanoprost compared to preserved glaucoma eye drops: the I2-month real-life FREE study
}

This article was published in the following Dove Press journal:

Clinical Ophthalmology

\section{Mario A Economou' \\ Helene Kolstad Laukeland ${ }^{2,3}$ \\ Iwona Grabska-Liberek ${ }^{4}$ \\ Jean-François Rouland ${ }^{5}$}

'Anterior Segment Department, St Erik's Eye Hospital, Karolinska Institute, Stockholm, Sweden; 2Department of Ophthalmology, University Hospital, Trondheim, Norway; ${ }^{3}$ Department of Laboratory Medicine, Norwegian University of Science and Technology, Trondheim, Norway; ${ }^{4}$ Department of Ophthalmology, Ophthalmology Clinic Postgraduate Centre of Medical Education, Warszawa, Poland; ${ }^{5}$ Department of Ophtalmology, Claude Huriez Hospital, University Hospital, Lille, France
Correspondence: Mario A Economou Anterior Segment Department, St Erik's Eye Hospital, Karolinska Institute, Polhemsgatan 50, 112 82, Stockholm Sweden

Tel +4686723000

Email mario-alexander.economou@sll.se
Background: Lack of efficacy due to bad compliance caused by intolerance issues is the main reason for a change to a better tolerated ocular treatment, such as using preservative-free (PF) eye drops.

Aim: To assess the efficacy and local tolerance after 12 months and patient satisfaction regarding local treatment tolerance and handling at inclusion and after 6 months of PF latanoprost compared to preserved glaucoma eye drops.

Methods: This was an international, prospective, and observational real-life study. Up to three visits, one at inclusion and two follow-up visits (one after 6 and one after 12 months) were planned. Efficacy, local tolerance, and patient satisfaction were the main evaluation criteria.

Results: Data from 721 patients were available for the statistical analysis. Overall, $64.8 \%$ (467/721) of patients switched treatment before inclusion: $62.2 \%$ in the preserved and $68.9 \%$ in the PF latanoprost group. IOP values were similar between PF latanoprost and preserved eye drops and remained stable at all visits. Ocular signs and symptoms improved after switching to PF latanoprost; the prevalence of conjunctival hyperemia was significantly lower $(P=0.0015)$ at both follow-up visits. At follow-up visit 1, 49.5\% of the patients who switched to PF latanoprost decreased or stopped the use of artificial tears. Satisfaction regarding tolerance in patients using PF latanoprost improved significantly after the switch from preserved eye drops to PF latanoprost ( $88.9 \%$ and $42.5 \%$, respectively, $P<0.0001$ ).

Conclusion: This first real-life study showed that PF latanoprost was as efficacious but better tolerated than preserved eye drops over a sustained period of 12 months, while providing a significantly higher patient satisfaction and potentially allowing improvement in the patient's daily life.

Keywords: glaucoma, prostaglandins, preservative-free latanoprost, patient satisfaction, conjunctival hyperemia, ocular surface diseases

\section{Introduction}

Glaucoma is a widespread, sight-threatening disease usually associated with an elevated IOP that, if not treated properly, potentially causes irreversible optic nerve and visual field damages. Management of the disorder requires life-long treatment, usually eye drops. ${ }^{1}$

A large range of eye drops, containing beta-blockers, alpha-2 agonists, carbonic anhydrase inhibitors, and prostaglandins, are available for treating glaucoma, and for more than 20 years, prostaglandin analogues have been successfully used as a first-line treatment in glaucoma patients. ${ }^{2-6}$ Despite their excellent systemic safety, local side effects induced by the active molecule itself and by their preserved formulations may be observed. ${ }^{7-9}$ Such side effects include alterations in the ocular surface, triggering 
inflammation and dysfunction of the conjunctival epithelium and leading to various other ophthalmological disorders including dry eye disease (DED), conjunctival swelling, and blepharitis. As a result, patient discomfort and dissatisfaction may lead to poor treatment compliance, treatment failure, and ultimately to disease progression. Moreover, all these features have been reported to have an impact on the patients' quality of life. . $^{70,11}$

To manage the patient discomfort and side effects related to preserved eye drops, artificial tears or anti-allergic eye drops are frequently used concomitantly to manage the associated eye disorders..$^{2,6,12,13}$ Therefore, high patient satisfaction regarding tolerability to treatment initiation is a key for a successful, continued, and stable therapeutic benefit in glaucoma. ${ }^{12}$

In 2011, the first preservative-free (PF) latanoprost formulation (Monoprost ${ }^{\circledR}$; Laboratoires Théa, ClermontFerrand, France) has been made available. Several Phase II and Phase III studies demonstrated that PF latanoprost has a similar efficacy while being better tolerated compared to preserved latanoprost. . $^{9,14,15}$

The present real-life study FREE (Follow-up of glaucoma patients tReated with Prostaglandins EyEdrops) assessed the efficacy and tolerability after 12 months of therapy with PF latanoprost compared to that of preserved eye drops in patients with glaucoma as well as patient satisfaction and local tolerability at inclusion and after 6 months.

\section{Methods}

This was a multicenter, international, prospective, noninterventional real-life study conducted between January 2014 and July 2016 in 300 ophthalmological private practice settings in France, the Netherlands, Norway, Poland, and Sweden. Investigators were selected on the basis of feasibility and representative geographical distribution.

The study was conducted in compliance with the recommendations for Good Epidemiological Practice issued by the International Epidemiological Association and legal local requirements for the conduct of epidemiological studies. ${ }^{16}$ Approval from ethic committees were obtained for Poland (KOMISJA BIOETYCZNA, Centrum Medyczne Ksztalcenia Podyplomowego - Warszawa), the Netheralands (Stichting CGR, Amsterdam and METC, Medische Ethische Toetsings Commissie - Er), Norway (Regionale Komiteer for Medisinsk OG Helsefaglig Forkningsetikk), and Sweden (Board for Ethics Review, EPN), while no ethic's committee approval was required for France. Detailed information about local legal requirements followed for this study is provided in Table S1. According to local legal requirements, written informed consent was obtained from patients in Poland prior to the data collection; patients from all other countries received written information but were not required to provide written informed consent. Handing out of the information letter was documented in the case report form.

Each participating ophthalmologist had to include up to 10 patients aged 18 years or older with a documented diagnosis of glaucoma or ocular hypertension according to the guidelines of the European Glaucoma Society. ${ }^{6}$ Patients who were included sequentially in the study had to have a glaucoma stabilized with any topical treatment and received oral information and an information letter. Moreover, patients should have provided oral, and where required, written informed consent.

The study planned for three visits. Inclusion visit and the first follow-up visit after $6 \pm 2$ months (follow-up visit 1) were to be attended by all included patients. According to French health authority requests for efficacy and safety follow-up, patients from France were not to attend follow-up visit 2, $12 \pm 2$ months after inclusion. Thus, this visit was only to be performed by patients from the Netherlands, Norway, Poland, and Sweden, thus prolonging the follow-up duration for 6 more months. These data were used for the 12-month follow-up.

The main objective of the study was the evaluation of the efficacy and tolerability, including ocular surface diseases (OSDs) characterized by abnormalities of the tear film or inflammation of the cornea, conjunctiva, or eyelid margins; conjunctival hyperemia; tear-film break-up time (BUT); and use of tear substitutes and of current glaucoma treatments up to 12 months of daily use. ${ }^{17}$

Demographic and glaucoma data of all participating patients were collected at inclusion.

At all three visits, ophthalmologists collected information about glaucoma treatments used the day of the visit, treatment changes, and concomitant use of tear substitutes. Moreover, ophthalmologists assessed in each eye and at all visits IOP and local tolerance through the occurrence of OSDs, BUT (classified into three groups: $<5$ seconds, 5-10 seconds, and $>10$ seconds), conjunctival hyperemia, and fluorescein staining, as well as chemosis, lid redness, scaling, or swelling. Symptoms assessed by patients on a 4-point scale (absent, mild, moderate, or severe) included blurred vision and pain or discomfort at instillation, foreign body sensation, burning, dry eye sensation, itching, photophobia, red eye, tingling, and watering between instillations.

Patient satisfaction concerning local tolerance to treatment was assessed at inclusion and follow-up visit 1 on a continuous VAS from 0 (bad tolerance) to 100 (good tolerance) by 
the patient. Moreover, the ophthalmologist asked the patient to rate on a 4-point scale ranging from very satisfied to very unsatisfied his/her satisfaction and reported the answer on the case report form. Patient satisfaction of treatment handling was assessed on the same scale at follow-up visit 1.

Statistical analyses were performed with $\mathrm{SAS}^{\circledR}$ version 9.3 or more for Windows. Continuous variables were described in terms of number, mean, and SD. Categorical variables were described in terms of absolute frequency and percentage by group. If applicable, a 95\% CI was calculated.

Logistic regression was used to determine whether patient satisfaction was related to other variables. ORs and $P$-values (both adjusted for multiple comparisons and non-adjusted) were reported.

\section{Results}

\section{Patient demographic and disease data at inclusion}

In total, 757 patients were recruited: 552 from France, 98 from Poland, 43 from the Netherlands, 40 from Sweden, and 24 from Norway. Data from 721 patients at inclusion, from 702 patients at follow-up visit 1 , and data from 240 patients at follow-up visit 2 were suitable for statistical analyses. Thirtysix (36) patients were excluded from the Full Analysis Set (FAS) population due to non-respect of inclusion criteria.

The overall mean age at inclusion was $66.6 \pm 10.92$ years, and $59.2 \%$ were females. A very large majority of patients $(92.5 \%)$ had primary open-angle glaucoma. Mean duration of glaucoma was overall $6.9 \pm 6.15$ years and merged mean IOP was $17.3 \pm 3.68 \mathrm{mmHg}$.

A majority of patients (63.0\%) used previous glaucoma treatments prior to their current treatment; $3.2 \%$ had already used PF latanoprost. Overall, 64.8\% (467/721) of patients switched treatment before inclusion, $62.2 \%$ in the preserved and $68.9 \%$ in the PF latanoprost group. The most common glaucoma treatments were preserved beta-blockers $(21.2 \%)$, preserved latanoprost $(20.7 \%)$, preserved travoprost $(9.8 \%)$, PF beta-blockers $(7.8 \%)$, and preserved bimatoprost $0.01 \%(5.6 \%)$. Treatment was changed for an average of $2.2 \pm 1.57$ times. Main reasons for changing treatment were insufficient efficacy (48.1\%) and local intolerance (46.4\%).

Detailed patient demographic and disease data at inclusion are provided in Table 1.

\section{Efficacy}

The mean IOP remained stable and similar during the longterm follow-up in both the preserved treatment and $\mathrm{PF}$
Table I Demographic and glaucoma data at inclusion

\begin{tabular}{|c|c|}
\hline Variables & $\begin{array}{l}\text { Prevalence } \\
\text { Total } \\
\mathbf{N}=72 \text { I }\end{array}$ \\
\hline \multicolumn{2}{|l|}{ Age (years) } \\
\hline $\mathrm{n}$ & 716 \\
\hline Mean \pm SD & $66.6 \pm 10.92$ \\
\hline Missing & 5 \\
\hline \multicolumn{2}{|l|}{$\operatorname{Sex}(\%)$} \\
\hline Female & $59.2 \%$ \\
\hline Male & $39.7 \%$ \\
\hline Missing & $1.1 \%$ \\
\hline \multicolumn{2}{|l|}{ Glaucoma type (\%) } \\
\hline Primary & $92.5 \%$ \\
\hline Angle closure & $0.5 \%$ \\
\hline Open angle (high and low tension) & $92.0 \%$ \\
\hline Secondary & $7.2 \%$ \\
\hline Exfoliative & $5.0 \%$ \\
\hline Pigmentary & $1.4 \%$ \\
\hline Other & $0.8 \%$ \\
\hline Missing & $2.1 \%$ \\
\hline \multicolumn{2}{|l|}{ Glaucoma stages (\%) } \\
\hline Early glaucoma $(<6 \mathrm{~dB})$ & $38.6 \%$ \\
\hline Moderate glaucoma $(6-12 \mathrm{~dB})$ & $13.4 \%$ \\
\hline Severe glaucoma $(>12 \mathrm{~dB})$ & $2.4 \%$ \\
\hline Missing & $43.5 \%$ \\
\hline \multicolumn{2}{|c|}{ Time since glaucoma diagnosis (years) } \\
\hline $\mathrm{n}$ & 622 \\
\hline Mean \pm SD & $6.9 \pm 6.15$ \\
\hline Missing & 99 \\
\hline \multicolumn{2}{|l|}{ IOP (eyes merged, $\mathrm{mmHg}$ ) } \\
\hline $\mathrm{n}$ & 1414 \\
\hline Mean \pm SD & $17.3 \pm 3.68$ \\
\hline Missing & 28 \\
\hline \multicolumn{2}{|l|}{ Previous treatment(s) (\%) } \\
\hline Yes & $63.0 \%$ \\
\hline No & $37.0 \%$ \\
\hline \multicolumn{2}{|c|}{$\begin{array}{l}\text { Number of patients who changed treatments and mean } \\
\text { number of change }\end{array}$} \\
\hline $\mathrm{n}$ & 442 \\
\hline Mean \pm SD & $2.3 \pm 1.60$ \\
\hline Missing & 7 \\
\hline
\end{tabular}

latanoprost groups. Mean IOP values at all visits for preserved eye drops and PF latanoprost eye drops are provided in Figure 1.

A subgroup analysis in patients treated for 12 months with PF latanoprost confirmed that the mean IOP remained 


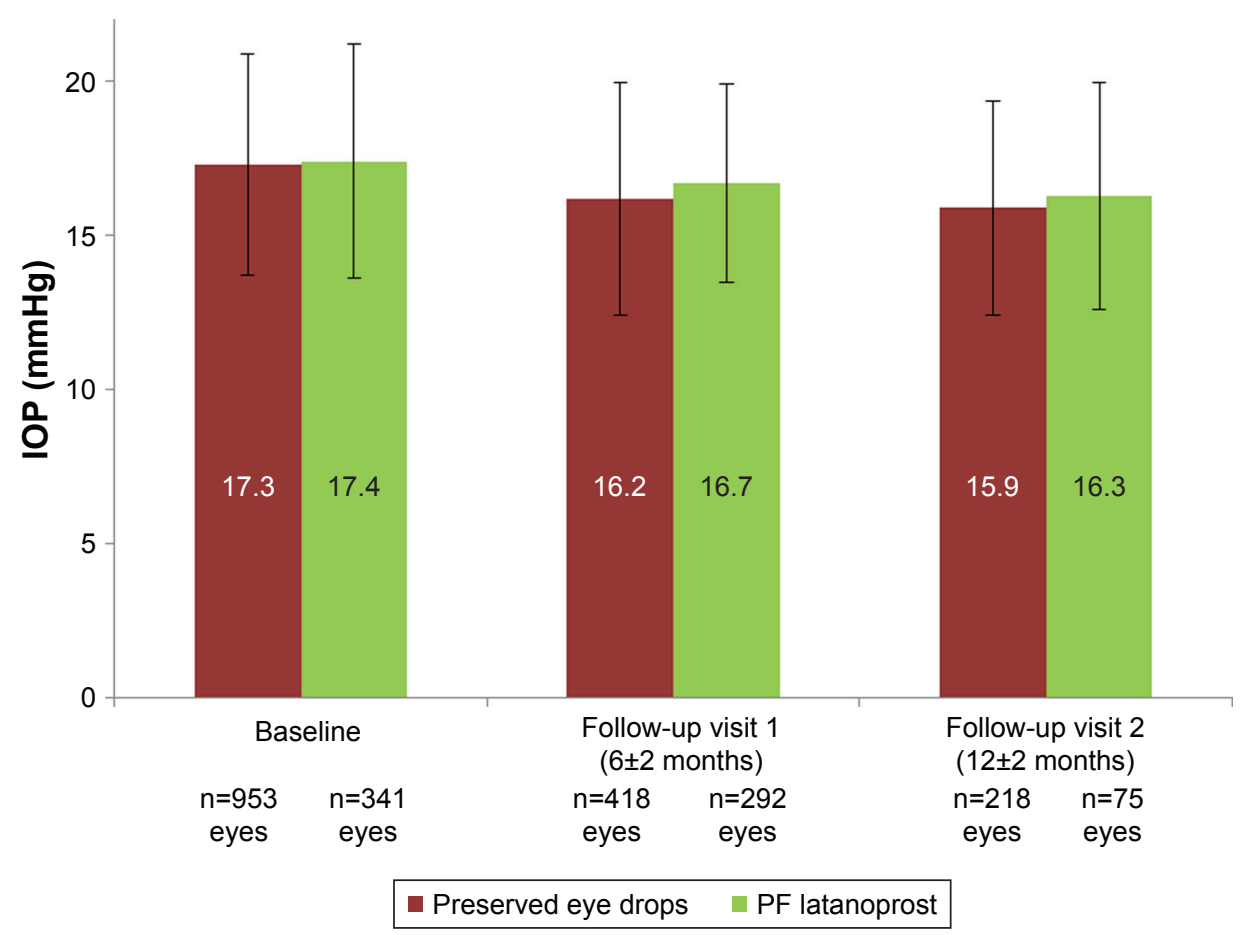

Figure I Intraocular pressure at inclusion, follow-up visit I, and follow-up visit 2 of patients with preserved eye drops and preservative-free latanoprost eye drops. Abbreviation: PF, preservative-free.

stable with $16.9 \pm 3.1 \mathrm{mmHg}$ at inclusion and $16.8 \pm 3.9 \mathrm{mmHg}$ at follow-up visit 2 .

\section{Safety and tolerability Investigator-reported ocular signs}

The prevalence of OSDs was always lower for patients using PF latanoprost than for those using preserved eye drops.

At inclusion, the prevalence of patients with OSDs was lower in the PF latanoprost group (56.8\%) than in the preserved eye drop group (76.0\%). At follow-up visit 1 , the prevalence of patients was $69.6 \%$ and $87.0 \%$, respectively. At follow-up visit 2, the prevalence of patients with OSDs had further decreased to $27.7 \%$ of patients in the PF latanoprost group and to $33.7 \%$ in the preserved eye drop group.

The prevalence of patients with no conjunctival hyperemia was significantly higher $(P=0.0015)$ at all study visits for patients using PF latanoprost compared to those using preserved eye drops at all study visits.

At inclusion, the prevalence of patients with no conjunctival hyperemia was higher in the PF latanoprost group $(67.2 \%)$ than in the preserved eye drop group (41.3\%). At follow-up visit $1,77.5 \%$ of the patients in the PF latanoprost group and $52.3 \%$ of the patients in the preserved group had no conjunctival hyperemia. At follow-up visit 2, the prevalence of patients with no conjunctival hyperemia had further decreased in both groups with $72.4 \%$ in the PF latanoprost group and $45.8 \%$ in the preserved group $(P<0.0015)$.

Figure 2 details the prevalence of patients with no conjunctival hyperemia at inclusion and both follow-up visits.

A large majority (more than $80.0 \%$ ) of all patients had no other ocular signs of local intolerance observed, at any visit.

For patients in the PF latanoprost group, BUT remained stable over time. The prevalence of patients with a BUT of more than 10 seconds was always higher in patients in this group than in the preserved group. At inclusion, 36.7\% of patients in the PF latanoprost group and $22.8 \%$ of patients in the preserved group had a BUT of more than 10 seconds. At follow-up visit 1, a BUT of more than 10 seconds was observed in $35.9 \%$ of the patients in the PF latanoprost group and in $28.7 \%$ of the patients in the preserved group. A further improvement was observed at follow-up visit 2; in the PF latanoprost group, a BUT of more than 10 seconds was observed in $36.7 \%$, while in the preserved group, it was observed in $35.6 \%$ of patients.

\section{Patient-reported ocular symptoms}

The prevalence of patients with no ocular symptoms upon and between instillations was always higher in the PF latanoprost group than in the preserved group. 


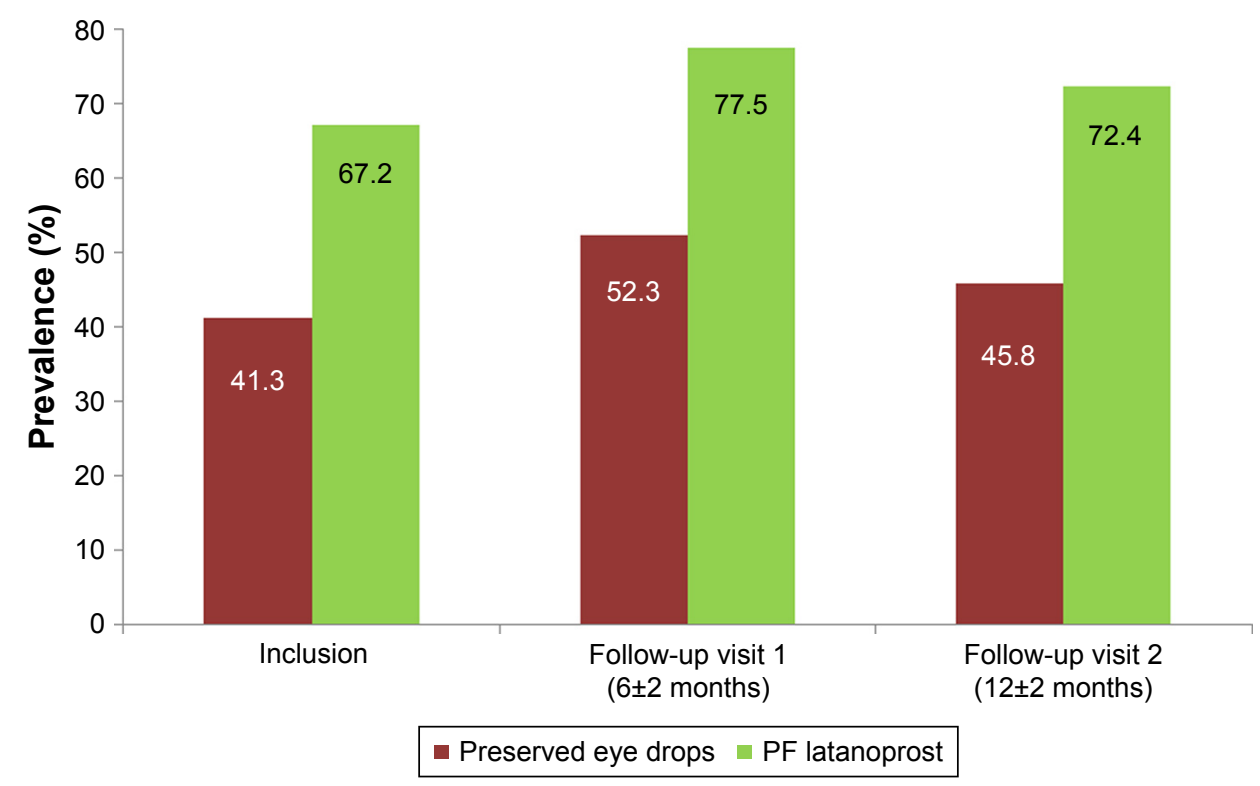

Figure 2 Prevalence of patients with no conjunctival hyperemia at inclusion, follow-up visit I, and follow-up visit 2. Note: The difference between the two treatment groups was statistically significant $(P=0.00 I 5)$ at all visits.

Abbreviation: PF, preservative-free.

\section{Upon instillation}

At inclusion, $72.7 \%$ of the patients in the PF latanoprost group and $56.8 \%$ in the preserved group reported no ocular symptoms upon instillation. A total of $35.6 \%$ of patients in the preserved group and $19.1 \%$ of patients in the PF latanoprost group reported pain or discomfort.

At follow-up visit 1, the prevalence of patients reporting no ocular symptoms upon instillation was $79.9 \%$ in the PF latanoprost and $66.8 \%$ in the preserved group.

At follow-up visit 2, the prevalence of patients with no ocular symptoms upon instillation was higher in the PF latanoprost $(93.5 \%)$ and remained lower in the preserved group $(76.9 \%)$.

Details are provided in Table 2.

\section{Between instillations}

At inclusion, 55.7\% of the patients in the PF latanoprost and $33.1 \%$ of the patients in the preserved group reported no ocular symptoms between instillations. The most common symptoms observed in the preserved group were red eye and tingling (29.1\% each), while dry eye accounted for $20.2 \%$. Conversely, in the PF latanoprost group, common incidences were dry eye sensation (15.3\%), red eye (11.5\%), and tingling (10.9\%).

At follow-up visit 1, a total of $66.2 \%$ of the patients in the PF latanoprost and $51.4 \%$ in the preserved group had no ocular symptoms reported. The incidence of blurred vision remained unchanged or was less commonly reported by patients treated with PF latanoprost (6.1\%) compared to patients using preserved treatments $(8.4 \%)$. The prevalence of patients reporting increased or unchanged pain or discomfort was lower with PF latanoprost (14.2\%) than for patients using preserved treatments $(25.7 \%)$.

At follow-up visit 2, the incidence of ocular symptoms reported at follow-up visit 1 remained similar for both groups.

Details are provided in Table 2.

Severity of ocular symptoms remained unchanged at both follow-up visits and in both groups.

\section{Concomitant use of tear substitutes}

At inclusion, $39.9 \%$ in the preserved and $33.3 \%$ in the PF latanoprost group used tear substitutes adjunctively to their glaucoma treatment. PF artificial tears $(66.8 \%)$ were the main tear substitutes.

At follow-up visit 1, 49.5\% of patients who switched to PF latanoprost declared having decreased or stopped the concomitant use of tear substitutes. A total of $34.4 \%$ who continued their treatment with preserved glaucoma treatment also declared that they continued the use of artificial tears; $31.6 \%$ used preserved and $68.4 \%$ PF artificial tears.

At inclusion, the mean VAS value for the PF latanoprost group was $85.5 \pm 15.37$ and $81.7 \pm 20.3$ for the preserved group. At follow-up visit 1, the mean value on the VAS scale had slightly increased in the PF group (87.9 \pm 9.75$)$ and remained unchanged in the preserved group $(81.7 \pm 20.3)$. 
Table 2 Patient-reported symptoms upon and between instillations at inclusion, follow-up visit I, and follow-up visit 2

\begin{tabular}{|c|c|c|c|c|c|c|}
\hline \multirow[t]{2}{*}{ Symptoms } & \multicolumn{2}{|l|}{ Inclusion visit } & \multicolumn{2}{|l|}{ Follow-up visit I } & \multicolumn{2}{|l|}{ Follow-up visit 2} \\
\hline & $\begin{array}{l}\text { Preserved } \\
\text { treatments (\%) }\end{array}$ & $\begin{array}{l}\text { PF latanoprost } \\
\text { (\%) }\end{array}$ & $\begin{array}{l}\text { Preserved } \\
\text { treatments (\%) }\end{array}$ & $\begin{array}{l}\text { PF latanoprost } \\
\text { (\%) }\end{array}$ & $\begin{array}{l}\text { Preserved } \\
\text { treatments (\%) }\end{array}$ & $\begin{array}{l}\text { PF latanoprost } \\
\text { (\%) }\end{array}$ \\
\hline \multicolumn{7}{|l|}{ (a) Upon instillation } \\
\hline No symptom & 56.8 & 72.7 & 66.80 & 79.90 & 76.90 & 95.30 \\
\hline Blurred vision & 9.1 & 8.2 & 5.20 & 7.70 & 7.50 & 2.30 \\
\hline Pain or discomfort & 35.6 & 19.1 & 25.70 & 14.60 & 15.80 & 4.60 \\
\hline Missing & 1.5 & 2.7 & 0.90 & 0 & 0.90 & 0 \\
\hline \multicolumn{7}{|c|}{ (b) Between instillations } \\
\hline No symptom & 33.1 & 55.7 & 51.4 & 66.2 & 64.8 & 55.8 \\
\hline Burning & 19.5 & 8.2 & 8.9 & 7.1 & 5.5 & 16.3 \\
\hline Dry eye sensation & 20.2 & 15.3 & 9.8 & 12.4 & 14.8 & 14.0 \\
\hline Foreign body sensation & 12.3 & 8.2 & 10.2 & 6.4 & 8.4 & 9.4 \\
\hline Itching & 13.1 & 6.0 & 10.3 & 7.8 & 11.6 & 11.6 \\
\hline Photophobia & 4.8 & 3.3 & 5.1 & 6.4 & 1.9 & 2.3 \\
\hline Red eye & 29.1 & 11.5 & 13.3 & 6.5 & 10.2 & 7.0 \\
\hline Tingling & 29.1 & 10.9 & 12.1 & 9.7 & 4.7 & 11.7 \\
\hline Watering & 12.5 & 7.7 & 7.9 & 8.0 & 7.4 & 9.3 \\
\hline Missing & 2.3 & 6.6 & 2.8 & 1.9 & 1.9 & 2.3 \\
\hline
\end{tabular}

Abbreviation: PF, preservative-free.

\section{Patient satisfaction}

The proportion of patients satisfied or very satisfied regarding tolerance to their current glaucoma treatment at inclusion was $88.6 \%$ in the PF latanoprost and $64.6 \%$ in the preserved group, and the difference was statistically significant $(P<0.0001)$.

Overall, $88.9 \%$ of the patients who switched to $\mathrm{PF}$ latanoprost after follow-up visit 1 were satisfied or very satisfied regarding the local safety of their new treatment compared to $42.5 \%$ who remained on preserved treatment. The difference was statistically significant $(P<0.0001)$.

At inclusion, the prevalence of satisfied or very satisfied patients with the handling of their glaucoma treatment was $91.3 \%$ for patients in the PF latanoprost and $89.6 \%$ for patients in the preserved group; it was $96.1 \%$ and $64.8 \%$ at follow-up visit 1 , respectively.

\section{Discussion and conclusion}

This international, multicenter, prospective, non-interventional study assessed for the first time the efficacy and tolerability of PF latanoprost for up to 12 months in real-life settings. Moreover, the study assessed the patient satisfaction regarding tolerance to their glaucoma treatment after a daily use during 6 months. Data from more than 700 patients confirmed that glaucoma is more frequently observed in women older than 60 years of age, suffering from a controlled early primary open-angle glaucoma. As recommended by the European Glaucoma Society guidelines, patients mainly used prostaglandins to treat their condition. ${ }^{6}$ Furthermore, study outcomes revealed that $40 \%$ of the patients used adjunctively artificial tears to treat their local tolerance issues and had their glaucoma treatment changed for several times due to mainly local tolerance issues, thus confirming observations made by Lemij et al. ${ }^{18}$

During the observation period, the IOP remained unchanged, regardless of the treatment, thus confirming the equivalent efficacy of PF latanoprost eye drops and of preserved formulations after 12 months of follow-up., ${ }^{9,14,19}$ PF latanoprost was better tolerated. This was confirmed through a lower incidence of clinically observed OSDs and conjunctival hyperemia compared to preserved eye drops, paralleling results by Muñoz-Negrete et al and Martinezde-la-Casa et al. ${ }^{19,20}$

Preservatives, especially benzalkonium chloride (BAK), the most used in ocular formulations, have a detergent effect on the lipid layer of the tear film, resulting in increased evaporation, DED, and concomitant eye disorders, requiring ultimately the concomitant use of artificial tears. ${ }^{21,22}$ The use of a latanoprost formulation, exempted of any preservative, especially BAK, resulted in a stabilized BUT of more than 10 seconds and an improved local tolerance confirming that DED is less common with PF latanoprost than with 
preserved eye drops, consequently leading to a reduced use of artificial tears. ${ }^{9,23}$

The low prevalence of patients reporting symptoms upon and between instillations with PF latanoprost paralleled findings already observed by Muñoz-Negrete et al in 2017. ${ }^{19}$

Patients using PF latanoprost were considerably more satisfied regarding their tolerance to treatment than those using preserved eye drops. The difference was statistically significant $(P<0.0001)$ at inclusion and after 6 months for those patients who switched from preserved to PF latanoprost between inclusion and follow-up visit 1, emphasizing the good tolerance profile of PF latanoprost through the absence of preservatives and their well-described toxicity. ${ }^{9,24}$ Furthermore, patients rated PF latanoprost eye drops more convenient to use than preserved eye drops regarding handling.

Increasing the patient satisfaction with their treatment may thus result in an improved quality of their life and in a better treatment adherence, which is an important issue in the long-term management of glaucoma as reported by Newman-Casey et al. ${ }^{25}$

The three main limitations of this study are its open-label design that may influence the investigators' judgment and the patients' feelings regarding their treatment and the fact that data from the French cohort from a follow-up visit after 12 months were not available due to regulatory constraints for France. A double-masked design might have been more appropriate but was not feasible in routine practice. Moreover, the present study design, as it was required by the different health authorities, did not allow for a standardized study duration, excluding a majority of patients from the 12 months' evaluation and thus limiting the sample size for evaluations to be made, thus leading to reliable study results for this visit. Also, the sampling method was not fully rigorous and the severity of patient-reported symptoms could have been collected. However, data obtained from this study based on the sampled and analyzed population at all three visits confirmed the demographic characteristics of the glaucoma population. Furthermore, it appreciating the fact that a prolonged use of preserved glaucoma eye drops causes OSDs as well as other ocular signs and symptoms while they do not provide any better clinical efficacy than PF latanoprost eye drops, thus supporting the clinical relevance of the findings in this study. ${ }^{26}$

In conclusion, this first real-life study confirmed the clinical benefit of PF latanoprost and its better local tolerance over preserved eye drops over a sustained period of 12 months.

PF latanoprost provided a significantly higher patient satisfaction, thus potentially allowing improvement in the patient's daily life.

\section{Acknowledgments}

The authors acknowledge the participation of the members of the FREE Study Group for patient recruitment, follow-up, and collection of data.

\section{Disclosure}

The authors received honoraria from Laboratoires Théa for their participation in the study and are consultants to Laboratoires Théa. The authors report no other conflicts of interest in this work. Support in study conduct was provided by Iris Pharma, La Gaude, France. Statistical consulting was provided by CAPIONIS, France, and assistance in manuscript preparation was provided by Karl Patrick Göritz, SMWS, France; all companies were compensated by Laboratoires Théa.

\section{References}

1. van der Valk R, Webers CA, Schouten JS, Zeegers MP, Hendrikse F, Prins $\mathrm{MH}$. Intraocular pressure-lowering effects of all commonly used glaucoma drugs: a meta-analysis of randomized clinical trials. Ophthalmology. 2005;112(7):1177-1185.

2. Arias A, Schargel K, Ussa F, Canut MI, Robles AY, Sánchez BM. Patient persistence with first-line antiglaucomatous monotherapy. Clin Ophthalmol. 2010;4:261-267.

3. Eyawo O, Nachega J, Lefebvre P, et al. Efficacy and safety of prostaglandin analogues in patients with predominantly primary open-angle glaucoma or ocular hypertension: a meta-analysis. Clin Ophthalmol. 2009;3:447-456.

4. Honrubia F, García-Sánchez J, Polo V, de la Casa JM, Soto J. Conjunctival hyperaemia with the use of latanoprost versus other prostaglandin analogues in patients with ocular hypertension or glaucoma: a meta-analysis of randomised clinical trials. Br J Ophthalmol. 2009;93(3):316-321.

5. Alm A. Latanoprost in the treatment of glaucoma. Clin Ophthalmol. 2014;8:1967-1985.

6. European Glaucoma Society Terminology and Guidelines for Glaucoma, 4th Edition - Chapter 2: Classification and terminology Supported by the EGS Foundation: Part 1: Foreword; Introduction; Glossary; Chapter 2 Classification and Terminology. Br J Ophthalmol. 2017;101(5):73-127.

7. Baudouin C, Labbé A, Liang H, Pauly A, Brignole-Baudouin F. Preservatives in eyedrops: the good, the bad and the ugly. Prog Retin Eye Res. 2010;29(4):312-334.

8. Jaenen N, Baudouin C, Pouliquen P, Manni G, Figueiredo A, Zeyen T. Ocular symptoms and signs with preserved and preservative-free glaucoma medications. Eur J Ophthalmol. 2007;17(3):341-349.

9. Rouland JF, Traverso CE, Stalmans I, et al; T2345 Study Group. Efficacy and safety of preservative-free latanoprost eyedrops, compared with BAK-preserved latanoprost in patients with ocular hypertension or glaucoma. Br J Ophthalmol. 2013;97(2):196-200.

10. Feldman RM. Conjunctival hyperemia and the use of topical prostaglandins in glaucoma and ocular hypertension. J Ocul Pharmacol Ther. 2003;19(1):23-35.

11. Jones L, Downie LE, Korb D, et al. TFOS DEWS II Management and Therapy Report. Ocul Surf. 2017;15(3):575-628.

12. Nordmann JP, Auzanneau N, Ricard S, Berdeaux G. Vision related quality of life and topical glaucoma treatment side effects. Health Qual Life Outcomes. 2003;1:75.

13. Zimmerman TJ, Hahn SR, Gelb L, Tan H, Kim EE. The impact of ocular adverse effects in patients treated with topical prostaglandin analogs: changes in prescription patterns and patient persistence. J Ocul Pharmacol Ther. 2009;25(2):145-152. 
14. Aptel F, Choudhry R, Stalmans I. Preservative-free versus preserved latanoprost eye drops in patients with open-angle glaucoma or ocular hypertension. Curr Med Res Opin. 2016;32(8):1457-1463.

15. Cucherat M, Stalmans I, Rouland JF. Relative efficacy and safety of preservative-free latanoprost (T2345) for the treatment of open-angle glaucoma and ocular hypertension: an adjusted indirect comparison meta-analysis of randomized clinical trials. J Glaucoma. 2014;23(1): e69-e75.

16. IEA. International Epidemiological Association: Good Epidemiological Practice (GEP), IEA Guidelines for properconduct in epidemiological research, November 2007; Available from: http://ieaweb.org/goodepidemiological-practice-gep/. Accessed March 7, 2018.

17. Craig JP, Nichols KK, Akpek EK, et al. TFOS DEWS II Definition and Classification Report. Ocul Surf. 2017;15(3):276-283.

18. Lemij HG, Hoevenaars JG, van der Windt C, Baudouin C. Patient satisfaction with glaucoma therapy: reality or myth? Clin Ophthalmol. 2015;9:785-793.

19. Muñoz Negrete FJ, Lemij HG, Erb C. Switching to preservativefree latanoprost: impact on tolerability and patient satisfaction. Clin Ophthalmol. 2017;11:557-566.

20. Martinez-de-la-Casa JM, Perez-Bartolome F, Urcelay E, et al. Tear cytokine profile of glaucoma patients treated with preservative-free or preserved latanoprost. Ocul Surf. 2017;15(4):723-729.
21. Pisella PJ, Pouliquen P, Baudouin C. Prevalence of ocular symptoms and signs with preserved and preservative free glaucoma medication. Br J Ophthalmol. 2002;86(4):418-423.

22. Wilson WS, Duncan AJ, Jay JL. Effect of benzalkonium chloride on the stability of the precorneal tear film in rabbit and man. Br J Ophthalmol. 1975;59(11):667-669.

23. Jee D, Park SH, Kim MS, Kim EC. Antioxidant and inflammatory cytokine in tears of patients with dry eye syndrome treated with preservative-free versus preserved eye drops. Invest Ophthalmol Vis Sci. 2014;55(8):5081-5089.

24. Pauly A, Roubeix C, Liang H, Brignole-Baudouin F, Baudouin C. In vitro and in vivo comparative toxicological study of a new preservative-free latanoprost formulation. Invest Ophthalmol Vis Sci. 2012; 53(13):8172-8180.

25. Newman-Casey PA, Blachley T, Lee PP, Heisler M, Farris KB, Stein JD. Patterns of Glaucoma Medication Adherence over Four Years of Follow-Up. Ophthalmology. 2015;122(10):2010-2021.

26. Thygesen J. Glaucoma therapy: preservative-free for all? Clin Ophthalmol. 2018;12:707-717. 


\section{Supplementary material}

Table SI Local legal requirements followed for the conduct of the study

\begin{tabular}{|c|c|c|c|c|c|}
\hline Countries & Health authorities & Ethical committee & $\begin{array}{l}\text { Data protection } \\
\text { agency }\end{array}$ & $\begin{array}{l}\text { Insurance } \\
\text { certificate } \\
\text { required }\end{array}$ & Comments \\
\hline France & $\begin{array}{l}\text { CCTIRS (Comité } \\
\text { Consultatif sur le } \\
\text { Traitement de l'Information } \\
\text { en matière de Recherche } \\
\text { dans le domaine de la Santé) }\end{array}$ & No & $\begin{array}{l}\text { CNIL } \\
\text { (Commission } \\
\text { Nationale de } \\
\text { l'Informatique et } \\
\text { des Libertés) }\end{array}$ & No & \\
\hline Poland & Not applicable & $\begin{array}{l}\text { Approval from KOMISJA } \\
\text { BIOETYCZNA (Centrum } \\
\text { Medyczne Ksztalcenia } \\
\text { Podyplomowego - } \\
\text { Warszawa) }\end{array}$ & $\begin{array}{l}\text { Local data } \\
\text { privacy laws }\end{array}$ & Yes & $\begin{array}{l}\text { Under the responsibility of the } \\
\text { national coordinator }\end{array}$ \\
\hline $\begin{array}{l}\text { the } \\
\text { Netherlands }\end{array}$ & $\begin{array}{l}\text { SOP obtained for } \\
5 \text { years }(2013-2018)\end{array}$ & $\begin{array}{l}\text { Approval from Stichting } \\
\text { CGR (Amsterdam) and } \\
\text { METC (Medische Ethische } \\
\text { Toetsings Commissie - } \\
\text { Erasmus MC) }\end{array}$ & $\begin{array}{l}\text { Local data } \\
\text { privacy laws }\end{array}$ & Yes & Non-WMO research studies \\
\hline Norway & $\begin{array}{l}\text { Norwegian Medicines } \\
\text { Agency (NOMA) }\end{array}$ & $\begin{array}{l}\text { Approval from } \\
\text { REK (Regionale } \\
\text { Komiteer for Medisinsk } \\
\text { OG Helsefaglig } \\
\text { Forkningsetikk) }\end{array}$ & $\begin{array}{l}\text { Trial registered } \\
\text { in a publicly } \\
\text { accessible } \\
\text { database }\end{array}$ & Yes & $\begin{array}{l}\text { There are currently no requirements } \\
\text { for non-investigational studies (NIS) } \\
\text { to be approved by NOMA } \\
\text { National code of practice: } \\
\text { Pharmaceutical self-regulation body: } \\
\text { The Association of the Pharmaceutical } \\
\text { Industry in Norway (LMI) } \\
\text { Guidelines for NIS of marketed } \\
\text { medicines (March 2008) }\end{array}$ \\
\hline Sweden & $\begin{array}{l}\text { Approval from the } \\
\text { Sveriges Kommuner } \\
\text { och Landsting or SKL }\end{array}$ & $\begin{array}{l}\text { Approval from Board } \\
\text { for Ethics Review (EPN) }\end{array}$ & $\begin{array}{l}\text { Local data } \\
\text { privacy laws }\end{array}$ & Yes & $\begin{array}{l}\text { There are currently no requirements } \\
\text { for non-investigational studies (NIS) } \\
\text { to be approved by MPA } \\
\text { Pharmaceutical Self-Regulation Body: } \\
\text { The Läkemedelsindustriföreningen } \\
\text { known as "LIF" }\end{array}$ \\
\hline
\end{tabular}

Abbreviations: SOP, standard operating procedure; CGR, Code Geneesmiddelen Reclame; WMO, Wet medisch-wetenschappelijk onderzoek met mensen (Medical Research Involving Human Subjects Act); MPA, Swedish Medical Products Agency.

Clinical Ophthalmology

\section{Publish your work in this journal}

Clinical Ophthalmology is an international, peer-reviewed journal covering all subspecialties within ophthalmology. Key topics include: Optometry; Visual science; Pharmacology and drug therapy in eye diseases; Basic Sciences; Primary and Secondary eye care; Patien Safety and Quality of Care Improvements. This journal is indexed on

Submit your manuscript here: http://www.dovepress.com/clinical-ophthalmology-journal

\section{Dovepress}

PubMed Central and CAS, and is the official journal of The Society of Clinical Ophthalmology (SCO). The manuscript management system is completely online and includes a very quick and fair peer-review system, which is all easy to use. Visit http://www.dovepress.com/ testimonials.php to read real quotes from published authors. 